\title{
THYSSEN: RELACIONES ENTRE MUSEO Y SALUD
}

\section{Thyssen: Relationship between museum and health}

\author{
Alberto Gamoneda \\ Museo Thyssen Bornemisza \\ agamoneda@museothyssen.org
}

Recibido: 15 de junio de 2011

Aceptado: 18 de julio de 2011

\section{Resumen:}

El Museo Thyssen Bornemisza de Madrid realiza un trabajo interdisciplinar que se enmarca los programas para públicos con necesidades especiales. Red de Públicos un espacio en el que las personas con diversidad funcional y con necesidades específicas, sus familias y las organizaciones y comunidades encuentran en el Museo un lugar en el que desarrollar al máximo sus capacidades, en el que acceden a los mismos servicios y cuentan con las mismas oportunidades que el resto de públicos. El Área de Investigación y Extensión Educativa colabora estrechamente con los diversos profesionales de los equipos de atención a los diferentes colectivos, con el objetivo de que descubran el Museo como un recurso útil en sus líneas de trabajo, un centro de encuentro comunitario donde convergen prestigio y visibilidad.

Palabras clave: red de trabajo, accesibilidad, visibilidad, comunidad, necesidades específicas, capacidades.

Gamoneda, Alberto 2011. Thyssen: Relaciones entre museo y salud. Arte, Individuo y Sociedad, Vol. 23, Núm. Especial, 245-255.

\begin{abstract}
:
Thyssen Bornemisza Museum works on interdisciplinary programs for public with special needs. Red de Públicos is a space where people with disabilities and special needs, their familias and their communities and organizations can develop their full potential, access to the same services and have the same opportunities than the rest of audiences. The Area de Investigación y Extensión Educativa works closely with professionals of user support teams with the main goal of discovering the Museum as a useful resource in their work lines, a Community meeting center where prestige and visibility are on.
\end{abstract}

Keywords: network, accesibility, visibility, Community, especial needs, habilities.

Sumario: 1. Introducción, 2. Contexto de acción, 3. Conclusiones. 


\section{Introducción}

En contextos como el actual hay cada vez un número mayor de voces e iniciativas que abogan por la necesidad del desarrollo y puesta en marcha de redes de trabajos interdisciplinares y transversales. Redes que reconstruyan la imagen cada vez más fragmentada y atomizada del ser humano y su vivencia para contrarrestar el exceso de especialización en que vivimos. En ámbitos como el cultural, artístico, educativo o sociosanitario, cada vez más voces de esos propios campos examinan y evalúan de una manera crítica y constructiva la función de sus disciplinas y la conveniencia y la necesidad de establecer lazos entre los profesionales de sus áreas, y en las visiones más avanzadas no sólo de los profesionales, sino de los usuarios que perciben sus servicios. Ese pensamiento crítico nos hace revisar de manera continuada la función y el sentido de nuestros espacios de acción. Si está claro que en el ámbito social o sanitario una vez pasada la medida de emergencia y crisis la función debería ser la integración normalizada en la vida comunitaria y la minimización del roll de enfermo o persona en riesgo de exclusión, muchas veces, la propia especialización del ámbito sociosanitario hace que sus propios usuarios se conviertan en profesionales de la enfermedad o de la exclusión viviendo su situación de una manera autoestigmática. Viéndose necesitados de la colaboración de otros espacios no específicos de la salud para minimizar la importancia de la etiqueta y el estigma.(Fig. 1)

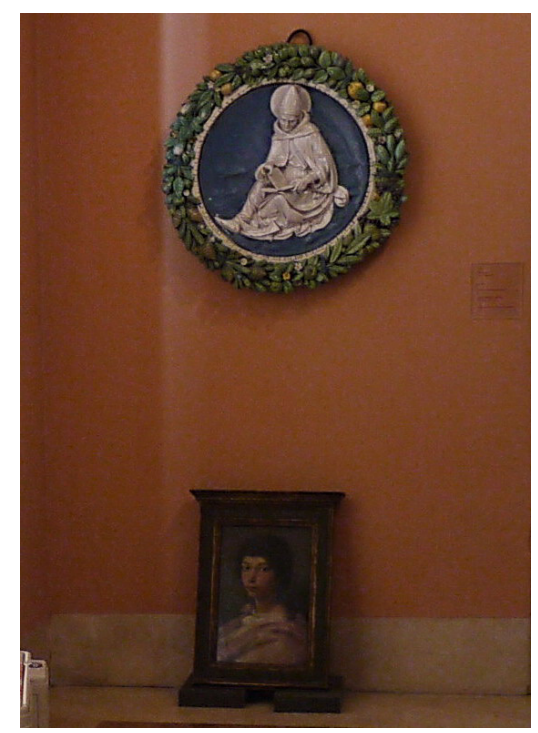

Fig. 1. *Fondo documental Educathyssen

Los Museos hoy en día se convierten en ámbitos comunitarios de primer orden, en una especia de Ágoras públicas de la modernidad (Fig.2) espacios de visibilidad que convocan un espectro amplio de la diversidad social de los espacios donde se ubican. Este espectro se ve potenciado por la función cultural y educativa que desarrollan 
los departamentos de educación generando vínculos entre la educación formal y no formal de una manera activa y transversal. Si entre educación y Museo ese vinculo es una realidad cada vez más fuerte. El desarrollo de líneas de trabajo de educación y acción social tiende la mano a los profesionales sociosanitarios y a los usuarios de los servicios que desarrollan. El paso lógico de todo este proceso es la generación de redes de trabajo interdisciplinares que tienen como objetivo cubrir las necesidades de esos usuarios a la vez que dotar a los profesionales de nuevos recursos y formas de trabajo y anclaje social para sus poblaciones, así como dotar al Museo de campos de investigación y de reflexión para encontrar nuevas utilidades prácticas y nuevos sentidos de existencia que sean extrapolables al resto de su público. (Fig.3)
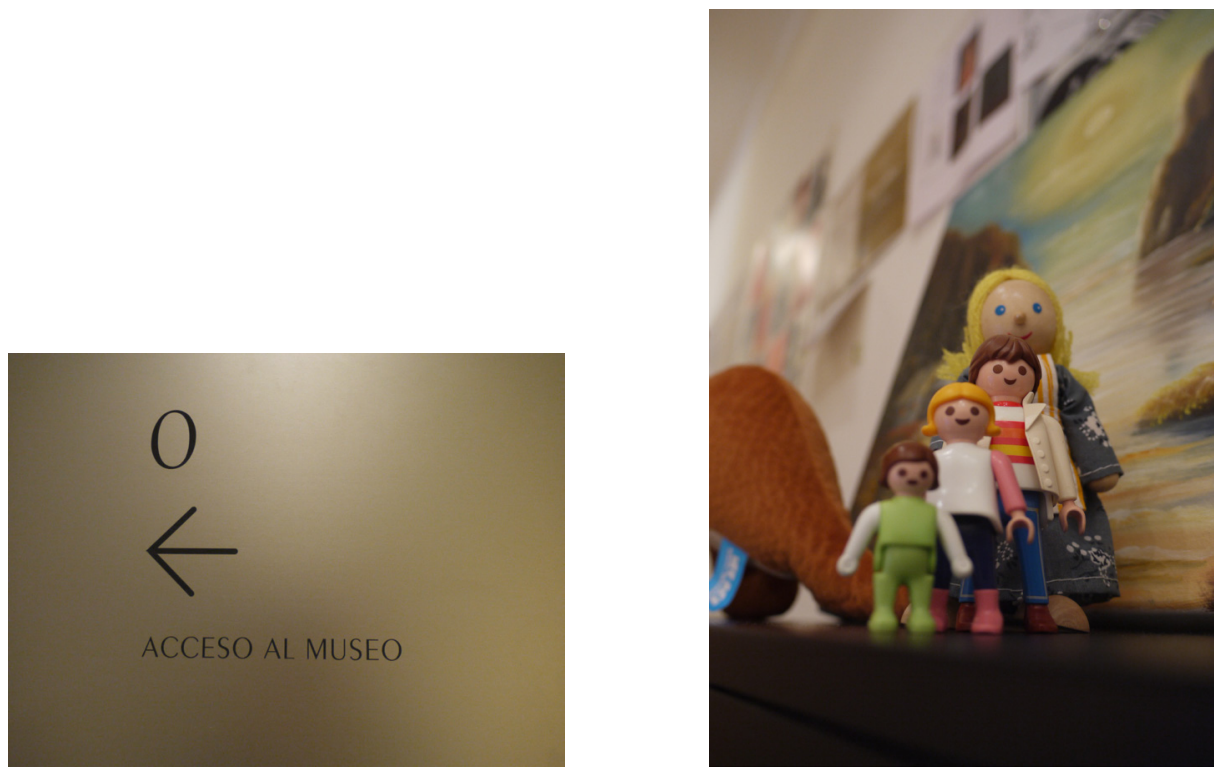

Fig. 2. y 3. *Fondo documental Educathyssen

\section{Contexto de la acción}

En el Museo Thyssen Bornemisza de Madrid es el área de Investigación y extensión educativa la que recoge ese trabajo interdisciplinar a través de las líneas de educación y acción en las que se enmarcan los programas para públicos con necesidades especiales y Red de Públicos. En estas líneas tienen una especial relevancia desde su comienzo las relacionadas con el ámbito sociosanitario y dentro de estas las específicamente relacionadas con recursos vinculados a ámbitos de salud. Cito sólo, a modo de muestra por cada tipo de recurso, alguna colaboración por ser más intensa, larga o en la que se han implementado vías de trabajo con el Museo de forma habitual, aunque el número de colaboraciones con diferentes recursos es mucho mayor. Desde su origen los programas surgen en coordinación con recursos del ámbito de la salud 
mental como centros de rehabilitación psicosocial (CRPS), del que es paradigmática la colaboración con el equipo profesional, los usuarios y familias del CRPS Latina, centros de rehabilitación laboral (CRL) entre las que destacan las experiencias con el CRL Latina, con una colaboración similar a la que tenemos con CRPS Latina y con el que se trabaja de manera coordinada en algunas actividades, Unidades hospitalarias de media estancia (UME) con la UME de Guadalajara donde la colaboración se hace con el equipo clínico (Fig. 4 ) los usuarios y los profesionales que llevan sus talleres de arte, o programas como el de atención integral a enfermedad mental (PAIEM) del centro penitenciario Navalcarnero 4 que comparten el ámbito de la salud con el penitenciario, En este caso las experiencias se hacen tanto en espacio penitenciario como en el Museo con los internos que tienen posibilidad de un régimen de salida. Importante en esta colaboración es la estrategia de trabajo coordinada con los profesionales de convertir los programas de salud mental del centro en la puerta de entrada del Museo al resto de los internos de otros programas.

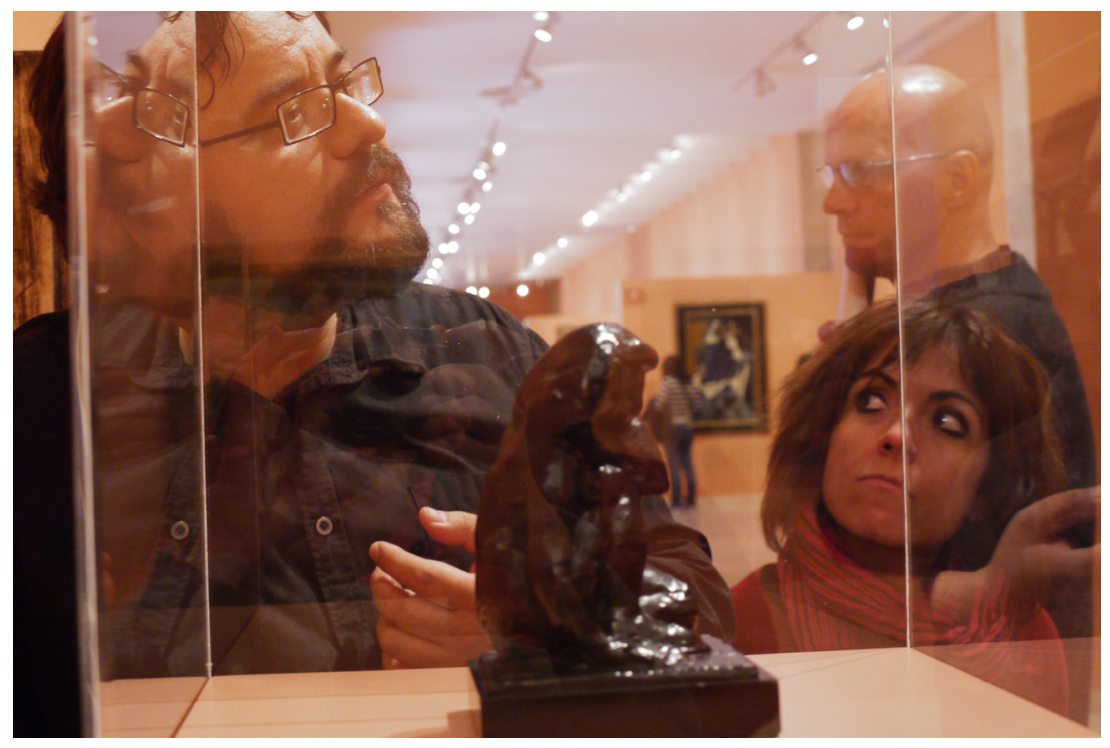

Fig. 4. *Fondo documental Educathyssen

Otro sector importante con el que se trabaja dentro del ámbito de la salud son las diferentes asociaciones vinculadas a diversas patologías y a la rehabilitación y atención de las mismas. Entre ellas se mantiene un estrecho contacto y líneas diversas de trabajo con la asociación Ayuda Afasia, la Fundación Lescer (Fig. 6), para personas con daño cerebral adquirido (D.C.A) con los que se desarrollan materiales sobre el Museo adaptados a D.C.A. y, más recientemente, con la asociación ADELA para enfermos de esclerosis lateral amiotrófica (E.L.A.) 


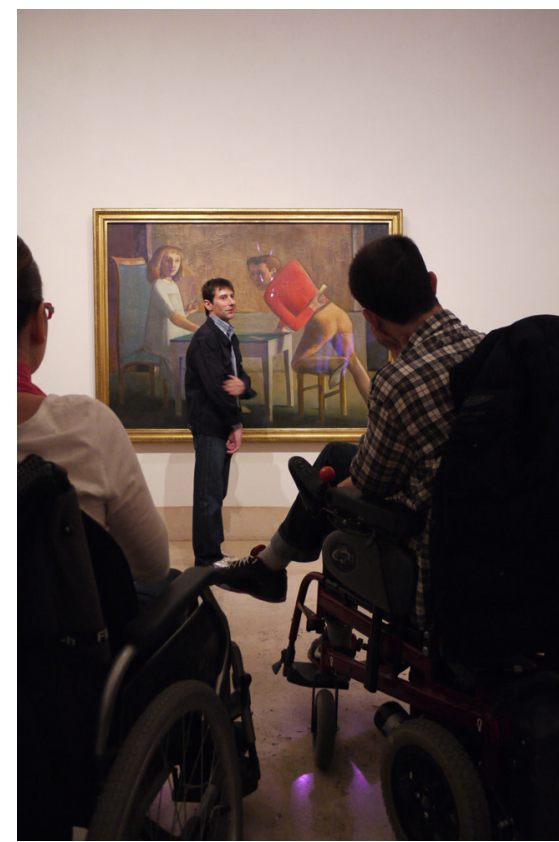

Fig. 5. *Fondo documental Educathyssen

También trabajamos con asociaciones y grupos de deterioro cognitivo y enfermedades neurodegenerativas como son AFA Alcalá con sus grupos de Alzheimer y Parkinson y los grupos de deterioro cognitivo de los centros de mayores de la zona centro de Madrid, estos últimos englobados dentro de una colaboración más amplia con los centros de mayores dependientes del área de servicios sociales de la zona centro del Ayuntamiento de Madrid.

En el diseño de las líneas de trabajo se colabora estrechamente con los diversos profesionales de los equipos de atención a los diferentes colectivos y en la medida de lo posible con los participantes, ya que nuestro objetivo es que entiendan y descubran el Museo como un recurso útil en sus líneas de trabajo y que entiendan el potencial de un espacio como el Museo que es, en la actualidad un centro de encuentro comunitario donde convergen prestigio y visibilidad.

En estos equipos de trabajo están médicos, psiquiatras, psicólogos, trabajadores sociales, Terapeutas ocupacionales, logopedas, enfermeros, técnicos de atención sociosanitaria, integradores sociales, animadores socioculturales... y en cuanto se puede, si es posible y se valora conveniente, las familias y los propios participantes. Siempre en función del equipo de trabajo del que disponga el colectivo, servicio o asociación, así como de sus objetivos. 
En la metodología de trabajo (Fig.6), como en el resto de programas del departamento, es básico el conocimiento de las necesidades, líneas de trabajo y características de cada grupo y colectivo, porque el diseño de la actividad se realiza en función de todo ello. Salvo que así se prefiera y forme parte de sus objetivos, se van a primar los contenidos de lectura visual de la imagen frente a los historiográficos o históricoartísticos que de salir a lo largo de la visita será como una deducción lógica a la que se llegue por el propio discurso del visitante o por que sea clave en la comprensión de la obra o apoye uno de los objetivos que se buscan con la visita.

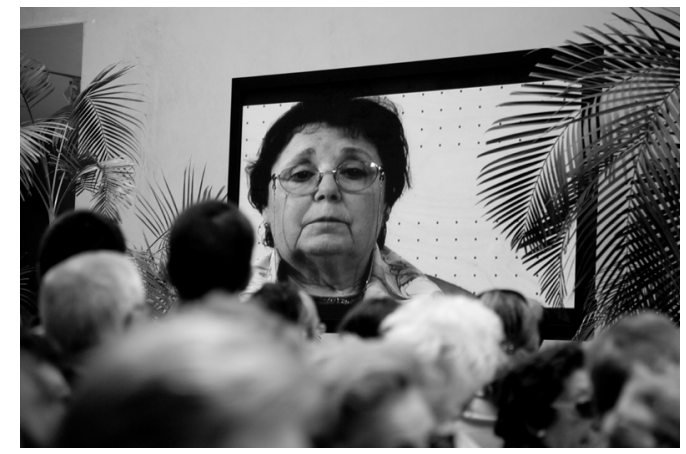

Fig. 6. Fotografía realizada por Hélène Desplechin

*Fondo documental Educathyssen

Temas como el punto de vista o la construcción de la propia imagen (Fig.7), el lugar que ocupa un espectador, las emociones y el color, artistas con diversidad funcional o en riesgo de exclusión, modos y maneras de mirar, la mujer en la pintura, afecto y sexualidad...son una pequeña muestra de algunos de los temas que nos han pedido y para los que hemos construido recorridos y talleres.

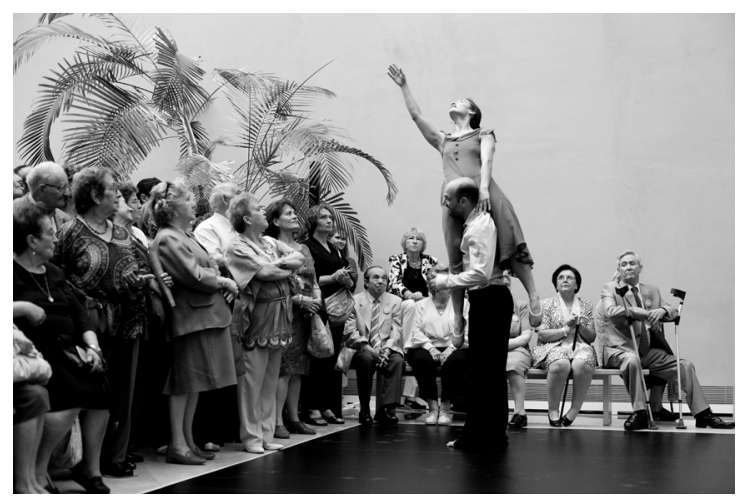

Fig. 7. Fotografía realizada por Hélène Desplechin *Fondo documental Educathyssen

Cuando hablamos de necesidades nos puede servir de ejemplo el caso de asociaciones como Ayuda Afasia (Fig.8)es obvio por las características de su público que la 
necesidad básica es la rehabilitación de áreas de lenguaje afectadas principalmente por lesiones en el área izquierda del cerebro, aunque hay afasias producidas por diversas etiologías. Por lo tanto, las estrategias de la visita irán encaminadas a que los participantes hablen de las obras, a que pierdan miedo a practicar su expresión oral en público y a potenciar su autoestima en ese sentido.

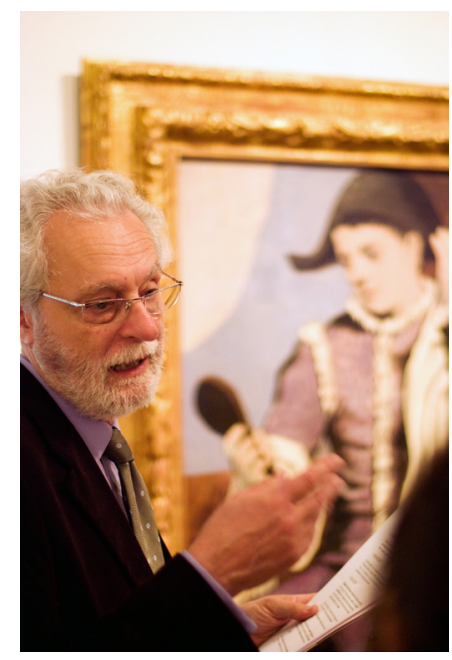

Fig. 8. Fotografía realizada por Hélène Desplechin *Fondo documental Educathyssen

Quizá la mejor manera de lograrlo sea la cesión del roll del educador como conductor de la visita a los diversos participantes, dentro de esa idea de la terapia ocupacional de: hacer para ser, cambiando su tarea de conductor de la visita a preparador de otros para que puedan hacer esa labor con uno o varios cuadros y para sus compañeros primero y luego para otros (Fig 9). En el caso de fundación Lescer que se circunscribe a pacientes con D.C.A. el trabajo con los profesionales de la asociación pasó además por descubrir que el trabajo de investigación sobre las obras y el Museo era un valor añadido, que ha cobrado aún más valor con la propuesta de elaborar materiales didácticos en fichas de Power Point adaptados a las necesidades de D.C.A. y que puedan servir como ficha de lectura fácil para otros colectivos, que tienen la oportunidad de descargarlas de Educathyssen y adaptarlas a sus necesidades.

Con CRPS, las propuestas y adaptaciones han sido múltiples. Desde el desarrollo de un juego de cartas dobles con imágenes del Museo con el fin de eliminar barreras verbales en la construcción de sus narrativas vitales, a la participación en el día de los Museos y las visitas para familiares y conjuntas entre usuarios y familias. En cada una de estas propuestas se respondía a un objetivo o necesidad concreta. En el caso de las cartas, poder utilizar las imágenes de la colección en el desarrollo de un recurso útil para los profesionales y que también pueda servir a otros públicos, en el caso de la participación en el Día Internacional de los Museos como guías voluntarios de una obra de la colección trabajar el empoderamiento, la visibilidad, la lucha contra el estigma y la superación de barreras, límites, miedos e impedimentos. En las visitas 
con las familias se ha trabajado en torno a los diferentes puntos de vista y a las miradas, en la idea de flexibilizar, dar espacio y potenciar la empatía de los familiares en sus relaciones con su familiar en el recurso. Es el paso previo a las visitas conjuntas en que unos y otros se descubren en un escenario diferente a los habituales y descubriendo en el otro el desempeño de capacidades y rolles hasta ese momento quizá creídos no posibles. De manera similar se trabaja con recursos como el P.A.I.E.M. y la U.M.E. Guadalajara, en este caso tratando de coordinarlas visitas tanto con sus talleres de creación literaria como plástica. Lo que nos ha llevado a trabajar la poesía y los cuadros de manera conjunta durante la visita continuando esta relación en sus talleres y en la planificación de las siguientes visitas.

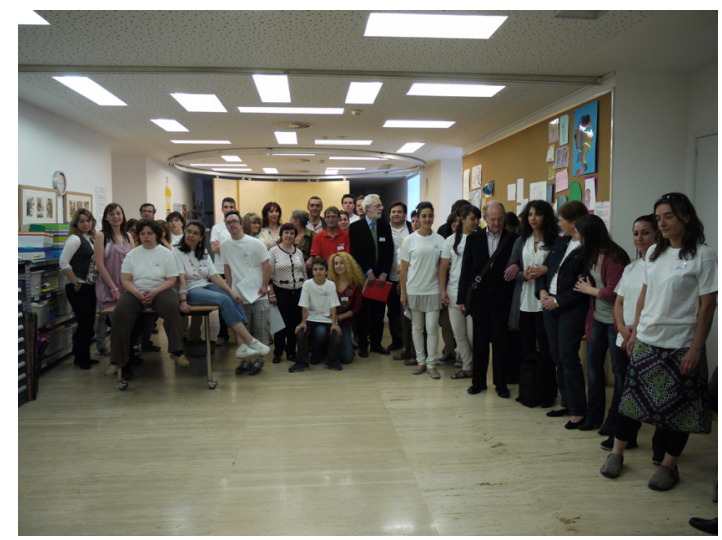

Fig. 9. *Fondo documental Educathyssen

En el trabajo con una asociación como A.D.E.L.A. las ideas de colaboración, una vez constatado el grado de satisfacción de los participantes en la visita, abarcan el poder cubrir a través del recurso otras necesidades como poder seguir haciendo accesible el Museo y sus campos de interés a lo largo de todo el proceso de evolución de la enfermedad, ya sea de manera presencial o a través de recursos web. Los desarrollos de los que hablamos con A.D.E.L.A. están aún en fase de planificación.

En cuanto a la manera de realizar las visitas, dentro de las adaptaciones necesarias, se trabaja en la misma línea que con otros públicos que acceden a las colecciones a través de los recursos del área. La idea con la que partimos siguiendo la máxima confuciana de me lo contaron lo olvide, lo vi y lo entendí, lo hice y lo aprendí, es la de la construcción del propio conocimiento por parte del participante a través de la experiencia, lo que los convierte en expertos de su propia vida, sus necesidades y la construcción de su conocimiento. Esa es la etimología de la palabra experto, de expertus y a su vez de experiri; para intentar, de prueba, persona sabia través de la experiencia. Y poca gente conoce sus propias vidas y sus necesidades como ellos y los profesionales que trabajan con ellos. 


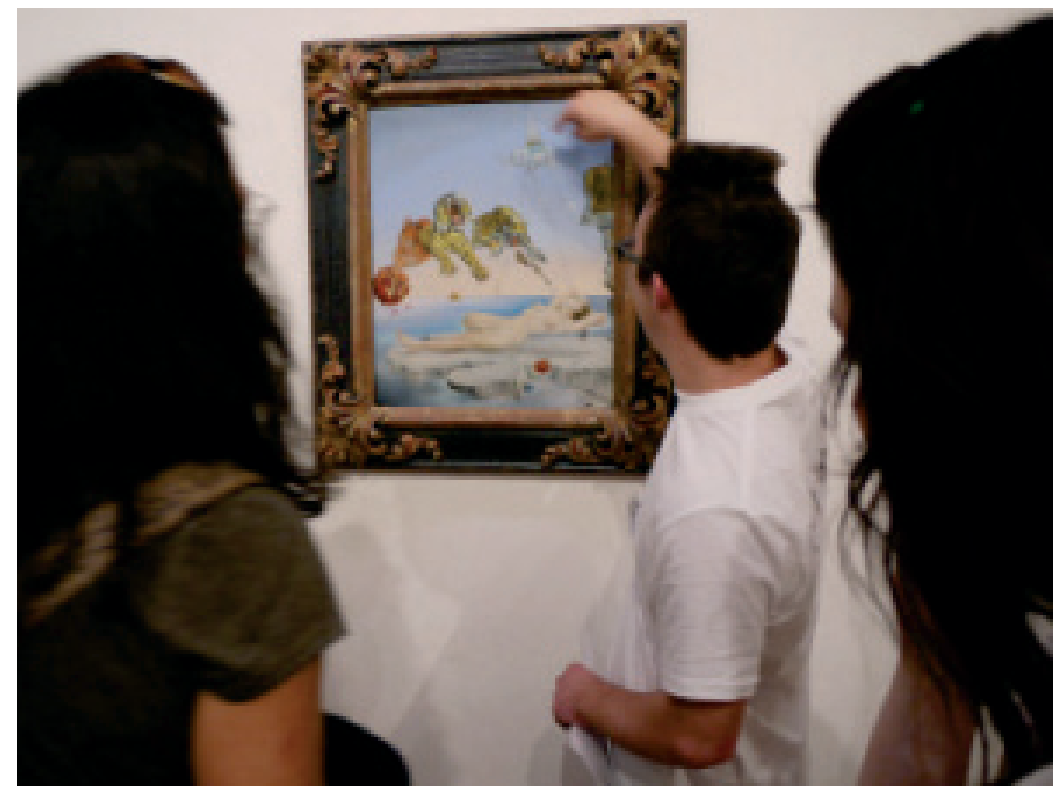

Fig. 10. *Fondo documental Educathyssen

La idea es reforzarles el bagaje con el que ya llegan al Museo y hacerles ver las múltiples posibilidades de ese conocimiento que portan a través de su experiencia. Como puede serles útil no sólo a la hora de interpretar imágenes si no a través de campos de analogía y experiencia dar puntos de vista y de respuesta a muchas de las situaciones que los rodean. Partimos de preguntas básicas como ¿Qué ves?, ¿Con qué ves? O ¿Qué crees que es lo más importante para este artista? Y ¿de qué crees que quiere hablarnos? De esas sencillas preguntas ante las obras van a salir los hilos de los que ir tirando para desenvolvernos durante la visita.

\section{Conclusiones}

En las devoluciones y evaluaciones que hacemos con posterioridad a la actividad una de las cosas que se valora de manera más positiva por los profesionales, a parte de la satisfacción con la misma y sus deseos de repetir, es el poder descubrir capacidades y posibilidades de desempeño que raramente tienen oportunidad de percibir en sus centros de origen.

Al hablar delante de un objeto externo (Fig.11) muchas de las barrera que algunos de ellos presentan en las sesiones de trabajo con los diferentes profesionales se minimizan e incluso desaparecen, permitiéndoles mostrar esas capacidades que otro modo habría sido difícil. Así como facilitar narrativas en torno a diferentes temas, que con la imagen como escusa permiten una libertad a la hora de la expresión que raramente se produciría de otro modo. 


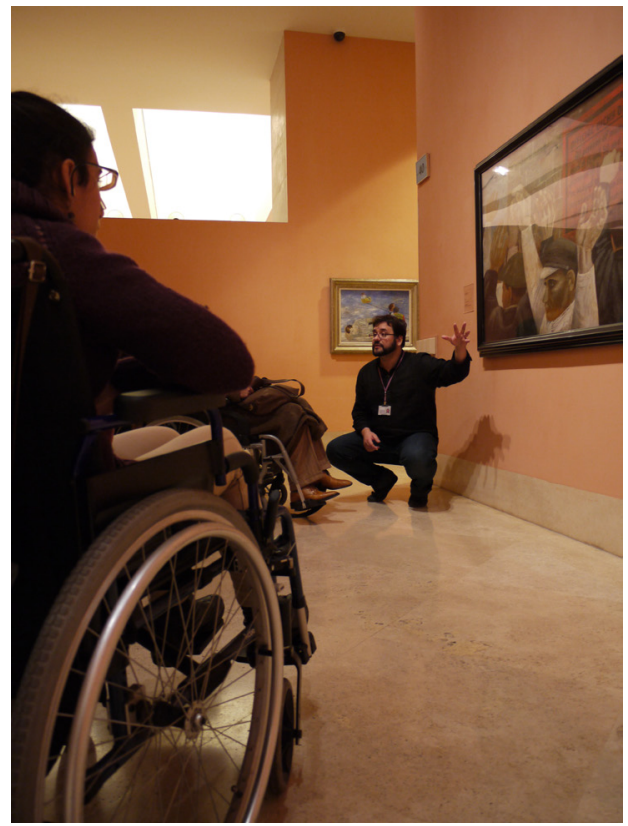

Fig. 11. *Fondo documental Educathyssen

Otra de las cosas que se valoradas es la posibilidad de salir del ámbito clínico y tener una actividad fuera de dicho ámbito e otro que vincula, como dicen Engeli y Ormaechea, dos elementos esenciales de nuestra naturaleza: lo comunitario como modo de estar en la vida, y lo simbólico como modo de pensarnos en la vida.

Quizá y como conclusión final, nada mejor que el fragmento de la narrativa de una de las usuarias de un Centro de Rehabilitación Psicosocial contando parte de su experiencia en los programas del Museo en colaboración con el CRPS.

Cuando salí de allí el subidón que llevaba era tal que casi me hacía andar sin tocar el suelo, agotada, pero satisfecha. Y ésta fue la etapa del logro.

No fue fácil, pero he aprendido, que para mí no hay ni habrá nada fácil de empezar ni hacer. Lo he de asumir porque si no volvería al principio.

Y os preguntaréis y ahora qué. Pues empiezo otra nueva etapa en el Museo, con xxxx y xxxxx y aunque desde Junio no estoy en mi mejor momento, con personas como las del Crps y xxxxx, cada una en su ámbito, que te explican, ayudan y todo lo que se os ocurra, y que han hecho que lo vea todo distinto y no me haya vuelto a encerrar en casa, sino que han hecho que entienda mi enfermedad, qué la produce y qué es lo que debo controlar (se aprende también de las adversidades), vamos todos juntos a dar otro pasito más hacia adelante en la acción de voluntariado que supongo será hacer un poco el trabajo que hacía xxxxxxx que se nos ha ido. Así que a pesar de que me cuesta un riñón no he dejado de ir a las actividades del Crps, porque son ocupaciones que te dan sentido y vamos, hoy estoy aqui hablando con todos vosotros, con bronquitis, que conste, que no me privo de nada coño. 
Resaltar por último una palabra que he aprendido gracias a xxx y que creo que expresa toda una vida. Esa pequeña palabra pero que abarca toda una vida y que además os sonará, es la resiliencia. Ese afecto que se necesita para no desarrollar una enfermedad o para salir de ella no la encontré nunca en mi familia. La he encontrado hace 3 años en el Crps y en el Thyssen este año donde he podido descubrir, cosa que creía que no habia, gente con integridad, buena, que se preocupa por los demás y no sólo de trabajar por dinero y que tiene esa iniciativa de crear situaciones como esta que ayudan, estoy segura que para ellos a demasiadas pocas personas porque no lo saben o no hay dias suficientes en el año, pero en realidad a muchas en calidad porque hacen que te sientas libre por un momento, por lo menos en mi caso de mi cabeza, que no os podéis imaginar lo que puede llegar a ser de necesario para descansar un poco. No solo cansa lo físico, también lo psíquico te deja agotada y ellos han hecho posible, ambos, xxxx y xxx que en el Thyssen junto a xxxx y xxxxxx, se palie ese círculo vicioso.

Como suelen decir cuando no tiene nada no necesitas nada, pero cuando encuentras y consigues algo, quieres más. Eso es lo que me está ocurriendo a mí, sólo espero no volver atrás y además ahora creo que se me escapa el tiempo. Cada día aprendo una cosa nueva de las personas observándolas y solo sé que si tú te das como persona, recibes la recompensa de que el otro te responda positivamente. En este momento es lo único que necesito. Afecto, cariño, aprender a darlo y recibirlo. Es la única forma de ser feliz o empezar a serlo, aunque no lo estés plenamente, que puede que sea imposible en todos los ámbitos, pero incluso no estando en mi mejor momento, intento ser mejor persona cada día, dentro de mi minusvalía. He de devolver lo que me han dado y me están dando. Hay que sentirse a gusto consigo mismo para poder hacer las cosas (exploración, competencia y logro) de forma correcta. 